\title{
Redesain Sistem Identitas Pasien sebagai Implementasi Patient Safety di Rumah Sakit
}

\section{Redesigning Patient Identity System as Patient Safety Implementation at Hospital}

\author{
Hesty Tulus ${ }^{1}$, Halimi Maksum ${ }^{2}$ \\ ${ }^{1}$ Rumah Sakit Umum Daerah dr. Abdoer Rahem Situbondo \\ ${ }^{2}$ Program Studi Magister Manajemen Rumah Sakit Fakultas Kedokteran Universitas Brawijaya Malang
}

\begin{abstract}
ABSTRAK
Identifikasi pasien merupakan bagian terpenting dari sebuah keamanan dalam memberikan sebuah pelayanan. Penandaan identitas pasien RS X di Jawa Timur baru dilaksanakan dalam beberapa bulan. Evaluasi dilakukan oleh bagian pendaftaran adalah $90 \%$ identitas pasien yang berupa gelang identitas tidak terpasang pada ibu hamil yang akan melahirkan di kamar bersalin. Data menunjukkan kurangnya sosialisasi di bagian rawat jalan dan yang memasang gelang identitas adalah petugas admisi. Dokumentasi yang berhubungan dengan identitas pasien di rumah sakit ini hanya Standar Prosedur Operasional (SPO) gelang identitas pasien menurut akreditasi 2007. Tujuan dari penelitian ini adalah mendesign ulang dokumen yang berkaitan dengan identifikasi pasien, melalui pembuatan dan penyempurnaan panduan dan SPO Identifikasi Pasien, yang sesuai dengan akreditasi 2012. Penelitian kualitatif dilakukandengan menggunakan braistroming secara bertahap melibatkan instalasi terkait, komite KPRS dan kelompok kerja akreditasi RS di Pokja SKP (Sasaran Keselamatan Pasien). Selanjutnya dilakukan sosialisasi dan simulasi pada perawat pelaksana di instalasi terkait. Hasil menunjukkan SPO yang diberlakukan tidak sesuai lagi dengan akreditasi 2012. Dilakukan pembuatan SPO tentang pemberian gelang identitas, pemasangan gelang identitas, pemasangan tanda risiko dan pelepasan gelang identitas dan tanda risiko pada pasien dewasa, menyusun panduan identitas pasien. Rumah Sakit perlu segera menetapkan Surat Keputusan Kebijakan pemberlakuan panduan atau pedoman dan SPO Identifikasi Pasien yang sesuai akreditasi 2012. Telah diikuti dengan sosialisasi dan simulasi pada para perawat pelaksana di instalasi terkait. Perlu Monitoring dan evaluasi oleh tim KPRS (Keselamatan Pasien Rumah Sakit) secara periodik untuk meningkatkan kepatuhan pelaksanaan SPO Identifikasi Pasien.
\end{abstract}

Kata Kunci: Identifikasi pasien, keselamatan pasien, panduan identitas pasien, standar akreditasi, Standar Prosedur Operasional (SPO)

\begin{abstract}
Patient identification is the most important part of security in providing services. Tagging patient's identity at $X$ hospital in East Java has just been implemented in a few months. Evaluation done by the registration officers showed $90 \%$ of patient identities in the form of identity band were not attached in pregnant women who will give birth in the delivery room. The data show of low socialization in the outpatient and the personnel to put the identity band are the admission officers. Documentation supporting the patient identification in this hospital is only Standard Operating Procedures (SOP) on patient identification band based on 2007 accreditation. The objective of this study is redesigning the documents relating to patient identification by creating and refining the guidelines and SOP on Patient Identification which is appropriate with 2012 accreditation. This is a quantitative research using brainstorming which done gradually by inviting related units, Hospital Patient Safety (KPRS) committees, and hospital accreditation working groups in the Patient Safety Goals (SKP). Furthermore, socialization and simulation on nurses in the related installation were carried out. The obtained result points out that SOP imposed was no longer in accordance with 2012 accreditation, therefore SOP on giving identity band, identity band installation, risk sign installation, and releasing the identity band and risk sign in adult patients was created and also preparing patient identity guidance. It is an urge to set Decree on implementation of policies or guidelines and appropriate SOP on Patient Identification fit to 2012 accreditation, and performing socialization and simulations for the nurses in related units. Monitoring and evaluation by Hospital Patient Safety (KPRS) team periodically for implementation on SPO Patient Identification compliance are needed.
\end{abstract}

Keywords: Accredutation Standard, patient identification, patient identification guideline, patients safety, Standard

Jurnal Kedokteran Brawijaya, Vol. 28, Suplemen No. 2, 2015; Korespondensi: Hesty Tulus. RSUD dr. Abdoer Rahem Situbondo, JL. Anggrek, No.68,68312, Kec. Situbondo,68312 Tel. (0338)671028Email: hestyrin@yahoo.co.id 


\section{PENDAHULUAN}

Akreditasi internasional memasukkan konsep keselamatan pasien menjadi salah satu penilaian standar sebuah rumah sakit. Keselamatan pasien yang didengungkan hampir 10 tahun yang lalu sekarang masih mendapat perhatian di beberapa rumah sakit yang akan melakukan akreditasi secara berkala setiap 3 tahun, selain dalam rangka pemenuhan kebutuhan pengguna jasa kesehatan. Semakin meningkatnya kebutuhan masyarakat akan kesehatan, semakin besar pula tuntutan layanan kesehatan umum agar dapat memenuhi keinginan masyarakat. Akreditasi KARS Versi 2012 mengacu pada sistem JCl (Joint Commission International), karena $\mathrm{JCl}$ merupakan badan yang pertama kali terakreditasi oleh International Standart Quality (ISQua) selaku penilai lembaga akreditasi internasional (1). Kelompok Sasaran keselamatan pasien meliputi 6 (enam) sasaran salah satunya adalah ketepatan identifikasi pasien. Identitas pasien merupakan standar keselamatan pasien yang sangat penting. Standar ini mengharuskan rumah sakit mengembangkan pendekatan untuk memperbaiki atau meningkatkan ketelitian identifikasi pasien (2). Kesalahan identifikasi pasien dapat terjadi di semua aspek diagnosis dan pengobatan. Ada beberapa keadaan yang dapat mengarahkan terjadinya error/kesalahan dalam mengidentifikasi pasien antara lain pasien dalam keadaan terbius atau tersedasi; mengalami disorientasi, atau tidak sadar sepenuhnya; memungkinkan tertukar tempat tidur, kamar, lokasi di dalam rumah sakit; mungkin mengalami disabilitas sensori; dan akibat situasi lain. Upaya mencapai identifikasi pasien yang baik dan benar memerlukan metode atau cara yang dapat dipercaya/reliable oleh karena itu rumah sakit harus mengembangkan pendekatan untuk memperbaiki atau meningkatkan ketelitian identifikasi pasien.

Meskipun kesalahan identifikasi pasien relatif tidak terlalu sering terjadi, tetapi dampak yang terjadi sering berakibat fatal, misalnya kematian dan sebagai penyebab pemicu kesalahan lainnya (3). Di United Kingdom tercatat 236 kejadian salah identifikasi per November 2003sampaiJuli 2005 (4). Berbagai bentuk akibat kesalahan identifikasi pasien tersebut meliputi: 1) pemberian obatpada pasien yang salah; 2) pembedahan dilakukan pada salah pasien (wrong person surgery); 3) pembedahan pada sisi yang salah (wrong site surgery), misal operasi pada ginjal yang sehat dan amputasi pada tungkai yang sehat; 4) pemeriksaan patologi anatomi pada pasien yang salah; 5) pemeriksaan imaging pada pasien yang salah; 6) pemberian transfusi darah pada pasien yang salah; 7) pengambilan spesimen pada orang yang salah; 8) penyerahan bayi pada orang tua yang salah (3).

Kesalahan identifikasi pasien sangat mungkin terjadi khususnya pada pelayanan di rumah sakit. Hal ini menyangkut beberapa faktor seperti kompleksitas dalam pelayanan dan keterbatasan petugas (fisik dan mental). Setiap hari beribu-ribu petugas laboratorium memproses pemeriksaan spesimen, baik pada fase preanalitik (pengambilan, penandaan, pengumpulan, interpretasi permintaan), analitik (pemprosesan sampel), maupun postanalitik. Ada beberapa puluh ribu kegiatan dalam sehari yang harus dilakukan oleh semua perawat, petugas radiologi, petugas farmasi yang semuanya memerlukan interaksi petugas dan pasien. Beberapa ribu pengisian lembar permintaan pemeriksaan (laboratorium, radiologi/imaging, resep obat) dalam sehari yang dikerjakan oleh petugas kesehatan dan beberapa ribu komunikasi terjadi dalam sehari antara dokter dengan dokter, dokter dengan perawat, dokter dengan pasien, perawat dengan petugas kesehatan lainnya atau dengan pasien. Pada semua proses demi proses tersebut sangat memungkinkan untuk terjadi suatu kesalahan dan kesalahan identifikasi adalah salah satu diantaranya(3).

Kesalahan identifikasi pasien sangat mungkin terjadi khususnya pada pelayanan dii rumah sakit. Hal ini menyangkut beberapa faktor seperti: kompleksitas dalam pelayanan dan keterbatasan petugas (fisik dan mental). Setiap hari berapa ribu petugas laboratorium memproses pemeriksaan spesimen, baik pada fase preanalitik (pengambilan, penandaan, pengumpulan, interpretasi permintaan), analitik (pemprosesan sampel), maupun postanalitik. Berapa puluh ribu kegiatan dalam sehari yang harus dilakukan oleh semua perawat, petugas radiologi, petugas farmasi yang semuanya memerlukan interaksi petugas dan pasien. Berapa ribu pengisian lembar permintaan pemeriksaan (laboratorium, radiologi/imaging, resep obat) dalam sehari yang dikerjakan oleh petugas kesehatan. Berapa ribu komunikasi terjadi dalam sehari antara dokter dengan dokter, dokter dengan perawat, dokter dengan pasien, perawat dengan petugas kesehatan lainnya atau dengan pasien. Pada semua proses demi proses tersebut sangat memungkinkan untuk terjadi suatu kesalahan dan kesalahan identifikasi adalah salah satu diantaranya (3).

Tujuan pokok mutu layanan RS X di Jawa Timur ini mengacu pada Standar Akreditasi Versi 2012 yaitu patient centered dan patient safety (5). Saat ini RS $\mathrm{X}$ tengah melakukan persiapan menyongsong akreditasi yang baru pada tahun 2014 yaitu Akreditasi KARS Versi 2012. Proses akreditasi ini dirancang untuk meningkatkan budaya keselamatan dan budaya kualitas di rumah sakit, sehingga senantiasa berusaha meningkatkan mutu dan keamanan pelayanannya. Sistem identifikasi pasien juga sedang mengalami proses pembenahan dan penyempurnaan secara terus menerus. Standar Akreditasi KARS untuk identifikasi pasien juga mengalami penyempurnaan. Hal ini dapat dilihat dari beberapa perbedaan Standar Akreditasi Versi 2007 dengan Standar Akreditasi Versi 2012 tak ada dalam Standar Akreditasi Versi 2007 semua identifikasi pasien hanya berpedoman pada data, dan difokuskan pada lembar rekam medis. Tindakan invasif yang akan dilakukan pada pasien tidak mengharuskan adanya verifikasi identifikasi pasien. Identifikasi pada bayi yang baru lahir hanya menggunakan cap kaki bayi dan cap jari ibu bayi. Standar Akreditasi Versi 2012 menggunakan sistem informasi yang berpusat pada data pasien. Identifikasi harus selalu dicocokkan ketika patugas akan melakukan tindakan invasif pada pasien, dengan cara verifikasi data pada gelang identitas pasien. Gelang Identitas pasien tersebut harus bisa menggambarkan data pasien berupa nama, tanggal lahir dan nomor rekam medis. Identifikasi bayi juga diberikan data gelang identitas bayi sesuai dengan jenis kelamin dan data ibu bayi (6).

Dokumen regulasi di rumah sakit yang berkaitan dengan identifikasi pasien adalah kebijakan, pedoman, panduan dan SPO (Standar Prosedur Operasional) (7). Pelaksanaan penyempurnaan standar identifikasi pasien sebagaimana tertuang dalam Standar Akreditasi Versi 2012, maka seluruh dokumen akreditasi yang mengacu pada standar 
identifikasi pasien harus dikaji ulang, hal ini sesuai dengan ketentuan evaluasi SPO dilaksanakan maksimal 3 tahun sekali. Rumah Sakit X saat ini telah menyusun SPO tentang identifikasi pasien rawat inap. Kebijakan atau Surat Keputusan sebagai payung hukum pelaksanaan identifikasi pasien dan pedoman/panduan sebagai petunjuk tehnis pelaksanaan identifikasi pasien belum tersusun. Pada SPO Identifikasi Pasien rawat inap ditetapkan bahwa pemasangan gelang identitas dilakukan oleh petugas pendaftaran (admisi). Untuk identifikasi pasien bayi baru lahir pemasangan gelang identitas dilakukan oleh petugas ruangan (perawat/bidan). SPO Identifikasi Pasien di Rumah Sakit X apabila dikaji ulang belum sesuai dengan Standar Akreditasi Versi 2012. Standar Akreditasi Versi 2012 tentang identifikasi pasien menyebutkan bahwa pemasangan gelang seharusnya dilakukan oleh perawat/bidan penanggung jawab pelayanan, bukan dilakukan oleh petugas administrasi yaitu bagian admisi.

\section{METODE}

Penelitian ini menggunakan pendekatan kualitatif dengan menggunakan braistroming secara bertahap dengan tujuan untuk mendapatkan kesamaan persepsi di setiap komponen yang terlibat dalam pemasangan gelang identitas. Komponen yang terlibat adalah instalasiinstalasi terkait dengan komite KPRS dan kelompok kerja akreditasi RS di bagian Pokja SKP (Sasaran Keselamatan Pasien). Selanjutnya dilakukan sosialisasi dan simulasi pada perawat pelaksana di instalasi terkait Tabel 1. Tahapan Penelitian.

\section{HASIL}

Hasil disetiap tahapan penelitian ini disajikan pada Tabel 2. Penelitian dilakukan dalam empat tahapan brainstorming untuk menganalisis permasalahan penggunaan gelang sebagai metode untuk meningkatkan ketepatan identifikasi dan solusinya. Hasil menunjukkan bahwa faktor kebijakan, kejelasan batasan dan penggunaan serta prosedur penggunaan menjadi akar permasalahan. Solusi dan simulasi penerapan prosedur penggunaan gelang identitas dengan berbagai kondisi dipandang sebagai solusi yang tepat untuk meningkatkan ketepatan sistem identifikasi pasien.

Forum sosialisasi dan simulasi dihadiri oleh Komite KPRS

Tabel 1. Tahapan brainstorming

\begin{tabular}{|c|c|c|c|c|}
\hline Tahap & Pelaksanaan & Tujuan & Peserta & Hasil akhir yang diharapkan \\
\hline 1 & 31 Oktober 2012 & $\begin{array}{l}\text { Menyesuaikan SPO } \\
\text { yang sudah dijalankan } \\
\text { dengan SPO yang } \\
\text { sesuai dengan } \\
\text { akreditasi versi } 2012\end{array}$ & $\begin{array}{l}\text { Komite KPRS; tim Pokja Sasaran } \\
\text { Keselamatan Pasien dan } \\
\text { didampingi oleh fasilitator } \\
\text { internal Akreditasi Rumah Sakit } \\
\text { seluruhnya berjumlah } 11 \text { orang. }\end{array}$ & $\begin{array}{l}\text { Mendapatkan SPO identifikasi } \\
\text { pasien yang sesuai dengan } \\
\text { akreditasi } 2012\end{array}$ \\
\hline 2 & 4 November 2013 & $\begin{array}{l}\text { Identifikasi } \\
\text { ketidakpatuhan } \\
\text { pemasangan gelang di } \\
\text { masing-masing } \\
\text { instalasi terkait. }\end{array}$ & $\begin{array}{l}\text { Wakil Direktur Pelayanan; } \\
\text { perwakilan Komite KPRS; Kepala } \\
\text { Bidang Keperawatan; Kepala } \\
\text { Seksi Asuhan Keperawatan; } \\
\text { Kepala Instalasi Admisi, PDE dan } \\
\text { RM; Kepala Instalasi Rawat jalan; } \\
\text { Kepala Instalasi Rawat Inap; } \\
\text { Kepala Instalasi IGD; Tim Pokja } \\
\text { Sasaran Keselamatan Pasien } \\
\text { yang semuanya berjumlah } 19 \\
\text { orang. }\end{array}$ & $\begin{array}{l}\text { Mendapatkan penyebab } \\
\text { ketidakpatuhan pemasangan } \\
\text { gelang identitas; mendapatkan } \\
\text { faktor-faktor yang menjadi } \\
\text { kendala tidak terpasangnya } \\
\text { gelang identitas pasien. }\end{array}$ \\
\hline 3 & 14 November 2013 & $\begin{array}{l}\text { Menentukan alur } \\
\text { pemberian, } \\
\text { pemasangan, dan } \\
\text { pelepasan gelang } \\
\text { identitas pasien }\end{array}$ & $\begin{array}{l}\text { perwakilan KPRS dan tim Pokja } \\
\text { Sasaran Keselamatan Pasien } \\
\text { didampingi oleh fasilitator } \\
\text { internal Akreditasi Rumah Sakit } \\
\text { yang berjumlah } 11 \text { orang. }\end{array}$ & $\begin{array}{l}\text { Mendapatkan kesepakatan } \\
\text { tentang alur pemberian, } \\
\text { pemasangan dan pelepasan } \\
\text { gelang identitas pasien pad } \\
\text { instalasi terkait. }\end{array}$ \\
\hline 4 & 19 November 2013 & $\begin{array}{l}\text { Mensepakati } \\
\text { beberapa ketentuan } \\
\text { yang harus dilakukan } \\
\text { pada saat pelaksanaan } \\
\text { pemasangan gelang } \\
\text { identitas }\end{array}$ & $\begin{array}{l}\text { Wakil Direktur Pelayanan; } \\
\text { perwakilan Komite KPRS Rumah } \\
\text { Sakit X; Kepala Bidang } \\
\text { Keperawatan; Kepala Seksi } \\
\text { Asuhan Keperawatan; Kepala } \\
\text { Instalasi Admisi, PDE dan RM; } \\
\text { Kepala Instalasi Rawat jalan; } \\
\text { Kepala Instalasi Rawat Inap; } \\
\text { Kepala Instalasi IGD; Tim Pokja } \\
\text { Sasaran Keselamatan Pasien } \\
\text { yang semuanya berjumlah } 16 \\
\text { orang }\end{array}$ & $\begin{array}{l}\text { 1. Kesepakatan penggunaan } \\
\text { identitas pasien } \\
\text { 2. Jika diperlukan merevisi } \\
\text { kembali penggunaan } \\
\text { gelang identitas pada bayi } \\
\text { dengan SPO yang sudah } \\
\text { diberlakukan } \\
\text { 3. Pengaturan kondisi darurat } \\
\text { di IGD sehingga gelang } \\
\text { identitas dan tanda risiko } \\
\text { tidak bisa terpasang di } \\
\text { ruang triase. } \\
\text { Kualitas respont time } \\
\text { supaya semua gelang } \\
\text { identitas dan tanda risiko } \\
\text { bisa terpasang. }\end{array}$ \\
\hline
\end{tabular}


Tabel 2. Hasil penelitian

Tahap Penelitian

1. Brainstroming ।

3 Brainstroming III

5 Sosialisasi dan Simulasi

2 Brainstroming II
4 Brainstroming IV

Hasil Brainstroming

1. Identifikasi dan evaluasi SPO, meliputi :

a. Pemberian dan pemasangan gelang identitas dilakukan oleh petugas admisi.

b. Penulisan pada gelang identitas masih manual sehingga sulit terbaca.

c. Tinta untuk menulis pada gelang identitas mudah luntur apabila terkena air.

d. Gelang identitas hilang pada saat proses perjalanan pasien dari rawat jalan/IGD menuju rawat inap.

e. Kesalahan dalam penulisan identitas pasien (kesalahan nama, jenis kelamin, alamat dan lainnya).

2. Penyesuaian SPO dengan Standar Akreditasi Versi 2012 dan kondisi di Rumah Sakit tentang pemberian, pemasangan dan pelepasan gelang identitas dan anda risiko.

3. Pengertian masing-masing SPO harus jelas dan sesuai dengan panduan penulisan SPO Akreditasi 2012.

4. Menentukan instalasi yang terkait dengan pemberian, pemasangan dan pelepasan gelang identitas dan tanda risiko.

1. Tiap-tiap instalasi yang terkait memaparkan hasil evaluasi ketidakpatuhan terhadap pemberian, pemasangan dan pelepasan gelang identitas pasien dan tanda risiko.

2. Peserta mengusulkan :

a. Perubahan bentuk gelang identitas, sebaiknya yang dengan barcode dan langsung bisa di print sehingga tulisan yang tertera di gelang identitas lebih jelas dan tidak mudah hilang

b. Tanda risiko yang digunakan adalah scotlite berwarna selain di admisi juga disiapkan di tiap instalasi yang terkait ( Rawat Jalan, IGD, dan Rawat Inap)

c. Identitas yang tertera pada gelang adalah nama, alamat dan nomor rekam medis pasien.

d. Pemberian gelang identitas diberikan oleh petugas pendaftaran/ admisi.

e. Pemasangan dan pelepsan gelang identitas dilakukan oleh perawat.

f. Penanggung jawab agar pasien mendapatkan gelang identitas yang baru apabila terdapat kemungkinankemungkinan gelang identitas hilang/rusak/tidak terpasang.

g. Alur pasien sesuai dengan kondisi Rumah Sakit X pada saat pemberian, pemasangan dan pelepasanan gelang identitas dan tanda risiko.

h. Hal-hal yang harus diperhatikan oleh perawat dalam langkah-langkah untuk memasang dan melepas gelang identitas dan tanda risiko.

1. Penyempurnaan Standar Prosedur Operasional pada masing-masing tindakan.

2. Kesepakatan/Persetujuan alur yang diusulkan dari rapat sebelumnya dan menyesuaikan dengan kondisi di rumah sakit untuk dimasukkan dalam SPO.

3. Menentukan alur pemberian, pemasangan dan pelepasan gelang identitas dan tanda risiko.

5. Penggunaan identitas pasien adalah nama dan alamat disesuaikan dengan KPT/SIM/Paspor.

6. Bayi menggunakan SPO tersendiri untuk pemberian, pemasangan dan pelepasan gelang identitas dan tanda resiko dan sudah tersusun. Jika masih ada yang belum sesuai kondisi di Rumah sakit akan diagendakan untuk merevisi kembali SPO tersebut.

7. Kondisi darurat di IGD sehingga gelang identitas dan tanda risiko tidak bisa terpasang di ruang triase selanjutnya akan diatur pada pedoman identitas pasien.

8. Perlu perbaikan kualitas response time supaya semua gelang identitas dan tanda risiko bisa terpasang.

I. Sosialisasi

A. Penjelasan singkat tentang:

1. Definisi gelang identitas dan tanda risiko

2. Macam dan warna gelang identitas dan tanda risiko

3. Alur pemberian, pemasangan dan pelepasan gelang identitas dan tanda risiko

4. Langkah-langkah pemasangan dan pelepasan gelang identitas dan tanda risiko

5. Kemungkinan-kemungkinan yang terjadi apabila gelang identitas dan tanda risiko hilang/rusak/tidak terpasang

B. Pemaparan Standar Prosedur Operasional :

1. SPO pemberian gelang identitas pada pasien dewasa

2. SPO pemasangan gelang identitas pada pasien dewasa

3. SPO pemasangan tanda risiko pada pasien dewasa

4. SPO pelepasan gelang identitas dan tanda risiko

II. Simulasi

Peserta dibagi menjadi 3 (tiga) kelompok. Masing-masing kelompok memperagakan di depan forum tentang alur dan cara memberi, memasang dan melepas gelang identitas dan tanda risiko. Masing-masing kelompok mendapatkan satu kasus yang di tentukan oleh penyaji.
RSUD dr. Soebandi dan para pelaksana dari instalasi terkait yaitu Kepala Instalasi rawat inap, Kepala Instalasi rawat jalan, Kepala Instalasi IGD, Kepala Perawat Pelaksanaan IGD dan para perawat penanggungjawab pelayanan. Masing-masing instalasi mengirim 2 (dua) peserta sebagai pelaksana atau perawat yang bertugas memasang dan melepas gelang identitas dan tanda risiko. Peserta yang hadir 35 (tiga puluh lima) orang. Pada saat sosialisasi diidentifikasi beberapa pertanyaan klarifikasi dari peserta dan telah disepakati solusi atau jawaban oleh Tim Pokja Keselamatan Pasien (Tabel 3). Pertanyaan yang berkembang tersebut sangat kontekstual karena terkait dengan potensi saat operasional dengan memperhatikan situasi yang sering ditemukan diantaranya dampak terhadap kecepatan pelayanan di IGD, faktor alergi, dan perluasan sosialisasi.Berikut adalah tanya jawab yang telah diberikan dan disepakati oleh tim Pokja Keselamatan Pasien: 
Tabel 3. Daftar pertanyaan dan jawaban sosialisasi SPO

\section{Pertanyaan}

1. Bagaimanakah kebijakan tentang gelang identitas dan tanda risiko bagi pasien yang mendapat izin pulang sementara dan akan melanjutkan perawatan?
2. Jenis tempat sampah manakah yang digunakan untuk membuang gelang identitas yang sudah dilepas dan dipotong kecil-kecil?

3. Bagaimanakah dengan sosialisasi terhadap tenaga medis yang lain, terutama para dokter?

4. Bagaimanakah solusi untuk gelang yang ternyata tidak bisa dikaitkan dan tanda risikonya rusak?

5. Bagaimanakah apabila kasus di IGD tidak sempat memasangkan gelang identitas dan tanda risiko di triase?

6. Bagaimanakah caranya supaya sosialisasi ini tidak mudah lupa karena banyak alur yang harus dihapal?

7. Bagaimana dengan pasien yang alergi terhadap gelang identitas itu sendiri?

\section{Jawaban}

1. Kebijakan untuk pasien yang diizinkan pulang sementara dan akan melanjutkan perawatan. Gelang identitas harus dilepas terlebih dahulu, jika akan melanjutkan perawatan maka pasien atau keluarga pasien harus mengkonfirmasi kepada kepala ruangan atau perawat penanggung jawab pelayanan di ruangan untuk memintakan kembali gelang identitas dan tanda risiko.

2. Jenis tempat sampah yang digunakan untuk membuang gelang identitas yang sudah dilepaskan dan dipotong kecil-kecil adalah tempat sampah infeksius.

3. Sosialisasi pemberian, pemasangan dan pelepasan gelang identitas dan tanda risiko pada tenaga medis terutama dokter akan diagendakan lebih lanjut oleh tim KPRS Rumah Sakit X.

4. Gelang yang hilang/rusak/tidak terpasang, sesuai dengan ketentuan SPO, perawat yang memintakan gelang identitas dan tanda risiko.

5. Kasus IGD yang tidak sempat dipasangkan gelang identitas dan tanda risiko akan dijelaskan dalam pedoman tentang identitas pasien.

6. Para pelaksana yang bertugas melaksanakan tugasnya sesuai SPO pemberian, pemasangan dan pelepasan gelang identitas dan tanda risiko adalah bagian dari Standar Akreditasi Versi 2012.

7. Pasien yang alergi terhadap gelang identitas. Gelang identitas dipasangkan menggunakan tali knur, dengan cara dikalungkan.
Simulasi dilalkukan oleh 3 (tiga) kelompok. Kelompok I memperagakan alur pasien rawat jalan yang akan mendapatkan tindakan invasif dalam mendapatkan, memasang dan melepaskan gelang identitas dan tanda risiko. Semua anggota kelompok diharapkan berperan aktif dalam memperagakan sesuai dengan SPO yang telah disampaikan sebelumnya. Kelompok II memperagakan alur pasien rawat inap yang masuk melalui poli spesialis dalam mendapatkan, memasang dan melepaskan gelang identitas dan tanda risiko. Pada kelompok ini ditambahkan kemungkinan-kemungkinan yang terjadi apabila gelang identitas dan tanda risiko hilang/rusak/tidak terpasang ketika pasien menuju ruang rawat inap. Semua anggota kelompok diharapkan berperan aktif dalam memperagakan SPO yang telah disampaikan sebelumnya. Kelompok III memperagakan alur pasien rawat inap yang masuk melalui IGD dalam mendapatkan, memasang dan melepas gelang identitas dan tanda risiko. Pada kelompok ini ditambahkan kemungkinan-kemungkinan yang terjadi apabila pasien akhirnya meninggal di ruang rawat inap. Semua anggota kelompok diharapkan berperan aktif dalam memperagakan sesuai dengan SPO yang telah disampaikan sebelumnya.

Setelah dilakukan brainstroming secara bertahap, sosialisasi, dan simulasi didapatkan rekomendasi sebagai wujud redesain sistem di RS X. Redesain sistem yang dibutuhkan untuk segera dilakukan sesuai dengan akreditasi 2012 adalah penyusunan landasan hukum identitas pasien berupa penetapan Surat Keputusan tentang kebijakan sasaran keselamatan pasien, penyusunan penetapan Surat Keputusan Panduan identitas pasien, penyusunan SPO pemberian gelang identitas, penyusunan SPO pemasangan gelang identitas dan tanda risiko serta penyusunan SPO pelepasan gelang identitas dan tanda risiko untuk pasien dewasa.

Penetapan landasan hukum dan SPO harus diikuti dengan sosialisasi agar ketetapan yang telah ditentukan oleh manajemen dapat dilaksanakan sesuai dengan langkahlangkah hasil brainstroming. Selain itu menganjurkan untuk selalu melakukan monitoring dan evaluasi secara periodik terhadap semua instalasi pelaksana untuk mengetahui tingkat kepatuhan dalam menjalankan SPO.

\section{DISKUSI}

Akreditasi rumah sakit versi 2012, mengacu pada JCI (Joint Commision International) yang lebih menitikberatkan pada: 1) Patient Centered Care, 2) Health Care Organization management, 3) Patient Safety Goals, 4) MDG (Millenium Development Goals). Keselamatan pasien rumah sakit adalah suatu sistem dimana rumah sakit membuat sistem pelayanan terhadap pasien agar lebih aman. Hal ini termasuk assesment risiko, identifikasi dan pengelolaan (1). Tujuan sistem keselamatan pasien rumah sakit: 1) terciptanya budaya keselamatan pasien di rumah sakit, 2) meningkatnya akuntabilitas rumah sakit terhadap pasien dan masyarakat, 3) menurunnya KTD (Kejadian Tidak Diinginkan) di rumah sakit, 4) terlaksanya programprogram pencegahan sehingga tidak terjadi pengulangan KTD (3).

Salah satu unsur terpenting dalam meningkatkan keselamatan pasien di rumah sakit adalah pengorganisasian sebuah sistem. Implementasi sistem pengorganisasian tersebut adalah dengan membentuk tim 
KPRS yang bertanggungjawab atas penerapan kegiatan keselamatan pasien. Terdapat 7 (tujuh) langkah menuju keselamatan pasien: 1) membangun kesadaran akan nilai keselamatan pasien, 2) memimpin dan mendudukung staff yang ada di rumah sakit, 3) mengintegrasikan aktifitas pengelolaan risiko, 4) mengembangkan sistem pelaporan, 5) melibatkan dan berkomunikasi dengan pasien, 6) melakukan kegiatan belajar dan berbagi pengalaman tentang keselamatan pasien, 7) mencegah cedera melalui implementasi sistem keselamatan pasien (8). Iklim keselamatan kerja juga merupakan salah satu penunjang tercapainya upaya menuju keselamatan pasien. Hal ini ditunjukkan dengan adanya persepsi pekerja atau perawat tentang kondisi dan situasi keselamatan kerja di organisasinya. Persepsi perawat yang positif ditunjukkan dengan memprioritaskan berupa katakata atau tindakan dan diselaraskan dengan persepsi mengenai kebijakan, prosedur dan tindakan-tindakan yang dilakukan (6).

Sasaran Keselamatan Pasien (SKP) yang pertama adalah ketepatan identifikasi pasien. SKP pertama yaitu rumah sakit mengembangkan sistem identifikasi pasien. Salah satu Penilaian SKP adalah pasien diidentifikasi menggunakan dua identitas pasien, tidak boleh menggunakan nomor kamar atau lokasi. Pada RS X setelah dilakukan brainstroming disepakati bahwa pasien diientifikasikan dengan menggunakan dua identitas dan nomor rekam medis, yaitu menggunakan nama dan alamat. Pemberian gelang tangan (wristband) di lengan, kaki atau tangan menjadi prosedur utama bagi pemberian identitas pasien, terutama bagi pasien yang akan diberikan tindakan invasif, pembedahan, pemberian transfusi, pemeriksaan imaging atau pasien yang tidak sadar. Ketentuan gelang tangan antara lain adalah: (a) Harus ditulis dengan menggunakan huruf balok. (b) Penulisan secara jelas dan tidak luntur apabila terkena air. (c) Harus mencakup paling sedikit 2 (dua) dari identitas diri pasien: nama, tanggal lahir, usia, jenis kelamin ataupun nomor register rekam medis. Meskipun ketentuan penulisan identitas pada gelang sudah dilakukan, bukan berarti gelang identitas menjadi satusatunya cara untuk dapat mencegah kesalahan identifikasi pasien. Di Australia Selatan semua pasien harus diidentifikasi dengan benar dan sesuai dengan asuhannya untuk menghindari resiko ketidaksesuaian dan mereduksi kerugian pasien. Sangat penting untuk mengidentifikasi pasien dengan benar sebelum melakukan pelayanan asuhan kesehatan. Paling tidak terdapat 3 identitas pasien meliputi nama, tanggal lahir dan nomor rekam medis. Semua master indeks pasien baik manual ataupun elektronik serta rekam medis harus memiliki 3 identitas pasien meliputi nama, tanggal lahir dan nomor rekam medis.Sistem barkode yang digunakan pada proses identifikasi pasien harus terhubung dengan informasi 3 identitas pasien tersebut dalam master indeks pasien elektronik (9)

Penyebab terjadinya kesalahan identifikasi pasien di kategorikan menjadi 3 hal yaitu: 1) kesalahan dalam penulisan dan administrasi, 2) kesalahan dalam verifikasi, dan 3) problem komunikasi. Kesalahan dalam penulisan dan administrasi dikelompokkan pada kesalahan dalam labeling, kesalahan dalam pengisian data, kesalahan dalam penuilisan angka berdigit dan pendokumentasian yang tidak lengkap. Kesalahan dalam verifikasi bisa terjadi pada prosedur verifikasi yang tidak ada dan tidak dilakukan. Hambatan dalam komunikasi yang sering dialami adalah hambatan bahasa, kondisi pasien dan kegagalan dalam serah terima/alih tugas (). Ketidakselarasan dalam komunikasi yang dilakukan oleh perawat kepada pasien bisa meningkatkan Kejadian Tidak Diinginkan (KTD) sehingga keselamatan pasien tidak tercapai. Selama perawatan kebutuhan pasien dapat terpenuhi apabila ditunjang dengan kelengkapan komunikasi informasi yang diberikan dan berhubungan dengan identitas resiko keselamatan (10).

Terdapat 7 langkah yang harus dilakukan rumah sakit untuk menciptakan sistem identifikasi pasien yang baik langkah pertama menyusun kebijakan untuk mengurangi risiko kesalahan identifikasi pasien dan menetapkan kapan identifikasi pasien harus dilakukan, yaitu pada saat pengambilan sampling darah, pengambilan transfusi darah, pengumpulan sampel yang berasal dari tubuh pasien (urin, dahak, darah, pus dll), pemberian obatobatan, prosedur bedah atau invasif, merujuk pasien, pemeriksaan radiologi/imaging, dan bayi baru lahir. Rumah sakit harus melakukan pelatihan tentang bagaimana melakukan penilaian ulang atau verifikasi terhadap penggunaan gelang identitas melalui orientasi dan pendidikan yang berkelanjutan. Rumah sakit perlu melibatkan pasien dan keluarga pasien agar dapat berperan aktif, yaitu dengan memberikan edukasi kepada pasien dan keluarga pasien tentang fungsi gelang identitas dan pentingnya menghindari kesalahan identitas diri, meminta pasien untuk menanyakan ulang dan mencocokkan sebagai tindakan verifikasi ulang terhadap data pasien. meminta pasien dan keluarga untuk selalu mencocokkan tindakan yang dilakukan terhadap pasien. Tindakan tersebut antara lain yang berkenaan dengan pemeriksaan, tindakan medis atau obat yang akan diberikan. Rumah sakit harus memastikan bahwa petugas melakukan pendataan dan penilaian ulang atau verifikasi dengan menggunakan komunikasi efektif. Komunikasi efektif petugas dilakukan sebelum pasien diberikan tindakan, misalnya pengambilan spesimen pemeriksaan laboratorium, pemberian transfusi. Tiga langkah terakhir adalah menggunakan dua sistem identifikasi pasien dan memastikan identitas yang dipakai pasen pada saat tindakan atau sesudah tindakan, membuat SPO (Standar Prosedur Operasional) tentang cara mengidentifikasi pasien, kejelasan penulisan terhadap apapun komitmen yang terjadi, misalnya menulis di lembar permintaan dan pemberian label (3).

Dari uraian diatas, faktor utama untuk mencegah terjadinya kesalahan identifikasi pasien adalah ketersediaan dan kepatuhan terhadap SPO dan pelaporan apabila terjadi kesalahan identifikasi pasien. Pelaporan kesalahan identifikasi pasien perlu sebagai dasar perbaikan SPO dan pembelajaran agar tidak terjadi lagi kesalahan identifikasi pasien. Beberapa manfaat yang dapat di peroleh apabila semua tindakan didasarkan pada kebijakan dan prosedur yang telah di tetapkan antara lain: keseragaman dan konsistensi tata kelola, kejelasan terhadap tugas yang dibebankan, mengurangi kesalahan dalam tindakan, menciptakan efisiensi waktu dan biaya, menetapkan pertanggungjawaban dari setiap tindakan, mempermudah menentukan pelatihan, menyiapkan 
kebijakan dan prosedur yang baru (8). Perawat membutuhkan standar dokumentasi sebagai petunjuk dan alat dalam pemeliharaan pencatatan /pendokumentasian sehingga ketepatan dalam pembuatan format pencatatan pembuatan laporan sebagai bukti pencatatan dan pelaporan tentang status pasien bisa digunakan sebagai alat komunikasi. Hal tersebut juga membantu meningkatkan Patient safety (11).

Selain berdimensi teknis, sebuah kebijakan dan prosedur memberikan dimensi yuridis, maksudnya adalah tidak hanya mengatur tata laksana dan tata kelola tetapi juga menjadi payung secara legal dan formal. Sekaligus melindungi sebuah tindakan yang mungkin terjerat bila melanggar hukum (7). Rumah sakit harus konsekuen terhadap pemverifikasian data pasien yang dilakukan sesuai dengan peraturan, SPO ataupun kebijakan. Hal ini disebabkan bahwa kelengkapan identitas pasien sangat berperan penting untuk menghindari kesalahan identitas (12).

Kondisi ini harus diperkuat dengan adanya dokumen regulasi yaitu semua dokumen yang harus disiapkan RS dalam pelaksanaan akreditasi RS. Dalam hal ini dokumen dibedakan menjadi 2 (dua) jenis, yaitu dokumen yang merupakan regulasi dan dokumen sebagai bukti pelaksanaan kegiatan. Selanjutnya dokumen yang dibahas disini adalah dokumen yang merupakan regulasi. Dokumen yang berkaitan dengan standar identifikasi pasien adalah dokumen kebijakan, pedoman, panduan dan SPO (7). Faktor lain yang harus diperkuat adalah kebijakan RS yang merupakan penetapan Direktur/ Pimpinan RS pada tataran strategis atau bersifat garis besar yang mengikat. Karena kebijakan bersifat garis besar maka untuk penerapan kebijakan tersebut perlu disusun pedoman/panduan dan prosedur sehingga ada kejelasan langkah-langkah untuk melaksanakan kebijakan tersebut. Kebijakan ditetapkan dengan peraturan atau keputusan

\section{DAFTAR PUSTAKA}

1. Direktorat Jenderal Bina Upaya Kesehatan Kementerian Kesehatan Republik Indonesia dan Komisi Akreditasi Rumah Sakit. Standar Akreditasi Rumah Sakit. Jakarta: Kementerian Kesehatan RI; 2011.

2. Departemen Kesehatan Republik Indonesia. Panduan Nasional Keselamatan Pasien Rumah Sakit. Jakarta: Departemen Kesehatan RI; 2005.

3. Tim RS RK Charitas Palembang. Menuju Pelayanan Kesehatan yang Aman, Kapita Selekta Keselamatan Pasien di Rumah Sakit. Yogyakarta: Kanisius; 2009.

4. World Health Organization. Patient Safety Solutions Preamble - May 2007. (Online) 2007. http://www.who.int/patientsafety/solutions/patient safety/Preamble.pdf.

5. Rumah Sakit Daerah Dr. Soebandi. Profil Rumah Sakit Dr. Soebandi Jember Tahun 2012. Jember: RSD Dr. Soebandi; 2013.

6. Sahara A. Faktor-faktor yang Berhubungan dengan Kepatuhan Perawat dan Bidan dalam Penerapan Kewaspadaan Universal/Kewaspadaan Sandar di
Direktur/Pimpinan RS. Kebijakan dapat dituangkan dalam pasal-pasal di dalam peraturan/keputusan tersebut, atau merupakan lampiran dari peraturan/keputusan (7). Aspek lain yang juga harus diperkuat adalah pedoman yang merupakan ketentuan dasar yang memberi arah bagaimana sesuatu harus dilakukan, dengan demikian merupakan hal pokok yang menjadi dasar untuk menentukan atau melaksanakan kegiatan. Panduan adalah merupakan petunjuk dalam melakukan kegiatan. Dengan demikian, dapat diartikan bahwa pedoman mengatur beberapa hal, sedangkan panduan hanya meliputi 1 (satu) kegiatan. Agar pedoman/panduan dapat dimplementasikan dengan baik dan benar, diperlukan pengaturan melalui SPO.Setiap pedoman/panduan harus dilengkapi dengan peraturan/keputusan Direktur/ Pimpinan RS untuk pemberlakukan pedoman/panduan tersebut. Bila Direktur/Pimpinan RS diganti, peraturan /keputusan Direktur/Pimpinan RS untuk pemberlakuan pedoman/panduan tidak perlu diganti. Peraturan/ Keputusan Direktur/pimpinan RS diganti bila memang ada perubahan dalam pedoman/panduan tersebut. Setiap pedoman/panduan sebaiknya dilakukan evaluasi minimal setiap 2-3 tahun sekali (7). Faktor keempat adalah standar prosedur operasional (SPO) sebagai suatu perangkat instruksi/langkah-langkah yang berurutan yang dibakukan untuk menyelesaikan suatu proses kerja rutin tertentu, atau urutan langkah-langkah yang benar berdasarkan konsesus bersama untuk melaksanakan berbagai kegiatan dan fungsi pelayanan, dan atau urutan langkah-langkah yang sudah diuji dan disetujui dalam melaksanakan berbagai kegiatan, sehingga membantu mengurangi kesalahan dan pelayanan sub standar. Penyusunan SPO secara umum bertujuan agar berbagai proses kerja rutin terlaksana dengan efisien,

si maka bisa dilakukan review atau revisi ulang terhadap SPO dengan melakukan brainstroming ulang dengan instalasi yang terkait.

Rumah Sakit Palang Merah Indonesia Bogor. Universitas Indonesia, Depok. 2011.

7. Komisi Akreditasi Rumah Sakit . Panduan Penyusunan Dokumen Akreditasi. Jakarta: KARS; 2012.

8. National Patient Safety Agency. Seven Steps to Patient Safety, an Overview Guide for Nhs Staff. London: NHS; 2004.

9. Goverment of South Australia. Patient Identification Guideline 2013. Adelaide: Goverment of South Australia; 2013.

10. Dewi M. Pengaruh Pelatihan Timbang Terima Pasien terhadap Penerapan Keselamatan Pasien oleh Perawat Pelaksana di RSUD Raden Mattaher Jambi. Jurnal Health \& Sport. 2012; 5(3): 646-655.

11. Lestari dan Rosyidah. Analisis Keptuhan Perawat pada Standar Asuhan Keperawatan di Unit Rawat Inap Kelas III RSU PKU Muhammadiayah Bantul Yogyakarta Tahun 2010. Jurnal Kesehatan Masyarakat. 2011; 5(1): 45-50.

12. Schulmeister L. Patient Misidentification in Oncology Care. Clinical Journal of Oncology Nursing. 2008; 12(3): 495-498. 